\title{
A New Home for Optical Microsystems Publications
}

\author{
Hans Zappe \\ Editor-in-Chief
}

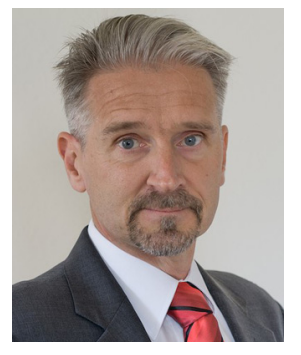

Welcome to the Journal of Optical Microsystems (JOM). With this first issue, we are launching a new publication which is positioned squarely in the thick of the engineering of optics and microsystems. If you are an optics researcher or developer working at the forefront of miniaturized systems, combining photonics with MEMS, conceiving of microsystems which incorporate novel optical materials, or applying nano-optics to exciting new applications, then you are in the right place.

There are already many optics journals, why does the world need another one? Indeed, optics is a vast field and we all publish and read papers in a broad variety of high-quality optics publications. Particularly for researchers addressing fundamental questions in optical science, we find an impressive array of publication venues. Those of us who work in classical optics, the bread and butter of one of the world's most important technologies, likewise have well-regarded established journals where we are likely to publish our work.

Yet the rapid rise of micro-technologies, ranging from microelectromechanical systems (MEMS) to micro-optics to micro-fluidics to the complex hybrids of microsystems engineering, has opened new vistas for optics on the micro scale. Based on a rich spectrum of advances in basic optical physics and coupled with the engineering capabilities ultimately derived from microelectronics, optical microsystems represent a diverse and highly interdisciplinary direction in engineering, much of which is difficult to pigeonhole into an established scientific discipline. And as such, many optical microsystems researchers, both those working in basic science and in engineering, both in academia and industry, when deciding where to publish their newest advances, often realize that their work falls outside the remit of the canon of established optics journals.

This is the gap which JOM now fills. At JOM, we are interested in all aspects of miniaturized optical systems, from materials and processes through devices up to complete systems. We are interested in basic science as well as advanced engineering, in useful new phenomena as well as novel applications. We are interested in academic research which opens new optical horizons as well as industrial developments that demonstrate the broad relevance of our work.

Starting a new journal is always an adventure, even if it addresses the interests of a significant portion of the scientific community. The publishers and editors ask themselves if an unknown name with no record and uncertain impact will take hold in the research community. Prospective authors ask themselves if anyone will ever read and cite their work. We at JOM are confident that, even after a year as historically awful as 2020, the answers to both are yes. Through the combination of a world-class editorial board, the support of a professional organization with the stature and experience of SPIE, and a select group of early authors willing to take the leap of faith with a new journal, JOM is poised to begin impacting the optical microsystems field.

We are now prepared to welcome the fourth term in our publication equation: our JOM readers. It is to you that our new journal is dedicated, and I hope that, behind the virtual cover image of our first issue, you will find plenty of exciting and inspirational optical microsystems research. And that you will be back for Issue 2 !

(C) The Authors. Published by SPIE under a Creative Commons Attribution 4.0 Unported License. Distribution or reproduction of this work in whole or in part requires full attribution of the original publication, including its DOI. 